\title{
Alleviating travel anxiety through virtual reality and narrated video technology
}

\author{
Ahn JC, Lee O \\ Department of Information System, Hanyang University, Seoul, Korea. ajchang@hanyang.ac.kr
}

\begin{abstract}
This study presents an empirical evidence of benefit of narrative video clips in embedded virtual reality websites of hotels for relieving travel anxiety. Even though it was proven that virtual reality functions do provide some relief in travel anxiety, a stronger virtual reality website can be built when narrative video clips that show video clips with narration about important aspects of the hotel. We posit that these important aspects are 1. Escape route and 2. Surrounding neighborhood information, which are derived from the existing research on anxiety disorder as well as travel anxiety. Thus we created a video clip that showed and narrated about the escape route from the hotel room, another video clip that showed and narrated about surrounding neighborhood. We then conducted experiments with this enhanced virtual reality website of a hotel by having human subjects play with the website and fill out a questionnaire. The result confirms our hypothesis that there is a statistically significant relationship between the degree of travel anxiety and psychological relief caused by the use of embedded virtual reality functions with narrative video clips of a hotel website (Tab. 2, Fig. 3, Ref. 26). Full Text in PDF www.elis.sk.

Key words: hotel room, websites of hotels, virtual reality, alleviating travel, video technology.
\end{abstract}

Travel is an activity that requires people to move to a certain location which can be familiar because of previous visit experience, but often might be a source of anxiety when people have to visit a completely unfamiliar place or a new accommodation even in the places that were previously visited (26). This kind of anxiety that arises from travel is called travel anxiety $(10,21)$. In this study we concentrate on travel anxiety that arises from the accommodation such as hotels. Even for people who have no fear of flying, the destination can be a mystery that might cause anxiety when the destination is the place that is located in a culturally apart area compared to travelers' own background. For example, somebody who resides in a western country tries to visit a place in northeast Asia and to stay in a hotel in the region will find the destination unfamiliar and feel anxious even when there are books and pictures about the city and the hotel available. Only real-life experience of visiting the hotel in the destination place will resolve this travel anxiety (17). However this is not possible in practice. In other words there is always a first time for visiting a new hotel in a new place, which will always cause some degree of travel anxiety in everybody. However nowadays thanks to the development of information technology, we can construct a website that provides otherwise unavailable information about the hotel and the place. Especially virtual reality technology $(4,18)$ which can be embedded into the hotel website allows potential travelers to have a chance to see what the inside of a hotel room or other

Department of Information System, Hanyang University, Seoul, Korea

Address for correspondence: J.C. Ahn, Department of Information System, Hanyang University, Seoul, Korea.

Phone: +82.02 .22202387$ areas of the hotel look like in an interactive and spatial way. By utilizing embedded virtual reality in a hotel website, near-real-life experience can be made and this experience will be very helpful for these travelers who regard the hotel and the destination city incomprehensible, i.e., insecure $(8,11)$. Namely travelers will have reduced travel anxiety due to the use of the embedded virtual reality website of a hotel (12). But even with the embedded virtual reality functions, the website of a hotel can be not fully informative. Showing pictures of various areas of a hotel is not enough to make travelers feel very familiar and secure. Therefore there should be another technique to enhance the embedded virtual reality website in order to create the experience of visiting the website as near-real-life as possible (22). In this research we introduce a new concept called the embedded virtual reality site with narrative video clips. This new technique adds video clips with narration for the sake of showing actual footages of a virtual traveler with narrations explaining what's going on while the camera is moving. This in-your-face style of exposure about the hotel and the surrounding neighborhood, in fact, throws a powerful punch to the viewers of the website on those aspects of insecurity that travelers might harbor deep inside their psych. These aspects of insecurity in this research are 1. Escape route 2. Surrounding neighborhood. Drawing from anxiety disorder literature (2), we posit that people with anxiety when inside a building should tend to look for an escape route and to make sure that they know where to go in case of emergency. For travelers with anxiety it is more aggravated since the hotel can be a total unknown building where they usually cannot find what kind of escape route is available even from the embedded virtual reality website of the hotel. In this research we incorporated a video clip of an escape 
route with narration into the embedded virtual reality function of a hotel website, which later was empirically proven to bring a strong psychological relief for people with higher anxiety. Another source of anxiety is surrounding neighborhood which is normally shown with a few pictures of the city where the hotel is located (5). Even with pictures of immediate neighborhood of the hotel, people still find the amount of information not satisfactory since it lacks vividness and hotel websites often carry little information about the very immediate neighborhood. In this research, we shot a video clip with narration of important landmarks that must be useful for travelers who would be in need of such. For example, the video clip shows a bus stop, a bank, a convenience store, a subway station, and a police station. This video clip is also footage of a virtual traveler with narrations explaining what the landmark on the screen is while the camera is constantly moving. This technique provides vividness and abundant information about the surrounding neighborhood of the hotel, which can make travelers feel very secure and familiar to a level of almost equal to real-life trip around the hotel. Empirical evidence was presented to show the effectiveness of the embedded virtual reality website with a video clip compared to the one without the video clip.

Travelers feel anxious in general since they are expected to go to some place that they are not familiar with. Especially people with high anxiety level find travelling far away or to unknown places more worrisome. Nowadays most hotels have their own websites to display what their hotels look like and show off nice features in a way to be more competitive in hotel industry. However instead of a lot of money invested in creation of visually stunning display of various areas of a hotel, it could be beneficial to travelers when the hotel website provide essential information to reduce travel anxiety. Most of travelers often do not have any experience of staying at the particular hotel that they reserved and adequate knowledge about the neighborhood surrounding the hotel, which should make travelers even more anxious (6). In addition to genuine travel anxiety, there are many people with anxiety disorder which generally includes agoraphobia and claustrophobia $(15,20)$. For this kind of people, their concern is to know if the escape route is clear and prepared. Because of these reasons that cause anxiety among travelers, we propose a hotel website that encompasses features that can reduce these anxieties. The Information System lab of Hanyang University in Seoul, Korea previously created an embedded virtual reality website where embedded pictures of escape routes were included in embedded virtual reality show segments in the hotel web page and proved its effectiveness by empirical experiment with human subjects.

This time, the IS lab has added more powerful features to the existing embedded virtual reality website. These features include two aspects as following:

1. When one clicks a window in a room that has been built with embedded virtual reality which shows 360 degree look of the hotel room by moving a mouse, a prepared video clip starts to be shown, which describes the neighborhood in Korean as well as in English. The video clip with narration must help the traveler understand the neighborhood where important milestones such as subway station, police station as well as convenience store are located and introduced (16).
2. Another aspect is about people with generalized anxiety disorder who are very interested in the escape route while they are staying in unknown places. To relieve this anxiety, the hotel room website with embedded virtual reality functions shows an entrance door of the hotel room and when the entrance door is clicked, the video clips with narration starts to play. The video clip shows a camera move that starts from the room, and a move into emergency exit and a move down through stairs until the camera reaches the first floor lobby. The narration kindly tells that the emergency exit is always open and the door knob is not a deadbolt (some people worry about the automatically closing door once it is opened). The narration also tells how many minutes to take in order to reach the first floor from the top floor so that the traveler get relief that it does not take very much time to get out of the hotel in case of emergency or sudden panic attack. And for people who have more severe anxiety disorder or height-phobia, the narration gently reminds that anybody who requests for lower floor rooms will be granted the lowest possible floor room.

We propose following hypotheses:

1. The embedded virtual reality website with narrated video clips is helpful for relieving travel anxiety.

2. The embedded virtual reality website with narrated video clips provides more psychological relief than the embedded virtual reality website without narrated video clips.

\section{Materials and methods}

The object of the embedded virtual reality website is a hotel called Itaewon Hotel in Seoul, Korea. This hotel is located in the area where a lot of foreign visitors frequent. Thus it is critical for the hotel to provide information about itself as well as surrounding neighborhood. An embedded virtual reality website was constructed even though the hotel's official website already existed for the purpose of this experiment. The URL of the embedded virtual reality with or without narrated video clips is as following: http://islab.hosting.paran.com/, http://islab2.hosting.paran.com/

This website is one page description of the hotel in Korean with pictures of the building as well as the first floor lobby. In addition, there is an embedded virtual reality picture that shows a typical hotel room in the hotel. The embedded VR room picture rotates and can be moved 360 degree by manipulating buttons in the picture. Inside the room picture, there are two points of interest where "click" sign is attached. When a user clicks on this icon, a pop-up page will show up. The first click sign on the entrance door of the room will show the escape route video clip from the entrance door to the ground floor with Korean and English narration. The second click sign on the front window will show the video clip of the surrounding neighborhood of the hotel with Korean and English narration. This video clip also introduces important milestones especially for travelers such as police station, subway station, as well as convenience store.

Following are captured pictures of this website:

Figure 1 is the page of the hotel website that contains the embedded virtual reality capable room picture with the entrance door shot where "click" symbol is attached. 




Fig. 1. Hotel webpage with embedded VR of a room with click" symbol on the entrance door.

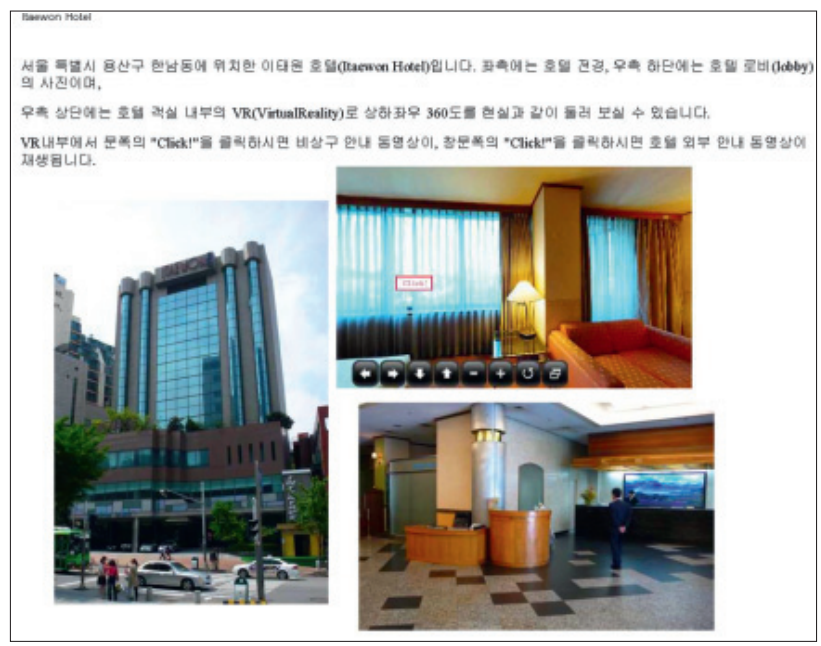

Fig. 2. Hotel webpage with embedded VR of a room with click" symbol on the front window.

Figure 2 is the page of the hotel website that contains the embedded virtual reality capable room picture with the front window shot where "click" symbol is attached.

When "click" symbol on the entrance door is clicked, a narrated video clip will be played with narration done in Korean as well as English. This video clip is to let the traveler know the escape route from his/her hotel room. The video starts from the hotel room to a corridor that leads to an emergency exit and to stairs. The narration reminds the viewer that the emergency door at every floor remains unlocked and is not a deadbolt meaning customers can not be locked out for customers who have strong claustrophobia. The narration also mentions the average time that takes for an adult to walk in a normal speed to reach from the top floor to the ground floor level so that customers can get precise estimate of escape time from their hotel room, which would make customers less anxious.

When "click" symbol on the front window is clicked, a narrated video clip will be played with narration done in Korean as well as
English. This video clip is to let the traveler be familiar with surrounding neighborhood of the hotel. The video starts from a map showing a red dot indicating the exact location of the hotel to a nearby bus stop, a bank, a convenience store, a subway station, and police station. The narration points out to the viewer what he/she looks at in the screen is an important place if the viewer actually stays in this hotel since one might have to go out to catch a bus, or subway, or to go out for a visit to a bank for money exchange, or for a trip to a convenience store for a cheap snack, or lastly, for a possible visit to police station for help. With all these useful information about useful places in the neighborhood, customers will feel less anxious and more secure since they will be familiar with the neighborhood.

\section{Research model and design}

\section{Research model}

This study is about alleviating anxiety of website embedded VR whether it has narrated video or not affecting intensity of anxiety and tries to observe the traits and difference of trust, website ability, benevolence etc. Also, it intends to develop prescription. Thus, we constructed variables based on the trust model of Mayer et al (14).

Trust is derived from ability, benevolence, and integrity. Thus, trust creator's ability, benevolent attitude to subject, and consistent principle's pursuit are connected to trust shaping. If trust relation is shaped, tendency to preserve relationship by accepting risk despite perceiving risk is presented (7) and this result makes influence on 3 factors of trust construct. It is main contents of Mayer et al.'s trust model, which trust is shaped and cumulated through this cyclical feedback process (14).

This study revised Mayer et al.'s trust model and designed like Figure 3. We intend to test research model about each cases whether the case has narrated video clip from website embedded VR or not. Also it tries to test the differences through comparative testing through prior cases.

There is a trust shaping cycle from ability of hotel website implemented VR, users' benevolent attitude to website, with expectation of consistent website offering. Once trust relationship is shaped, we forecast that tendency to visit and lodge to unfamil-

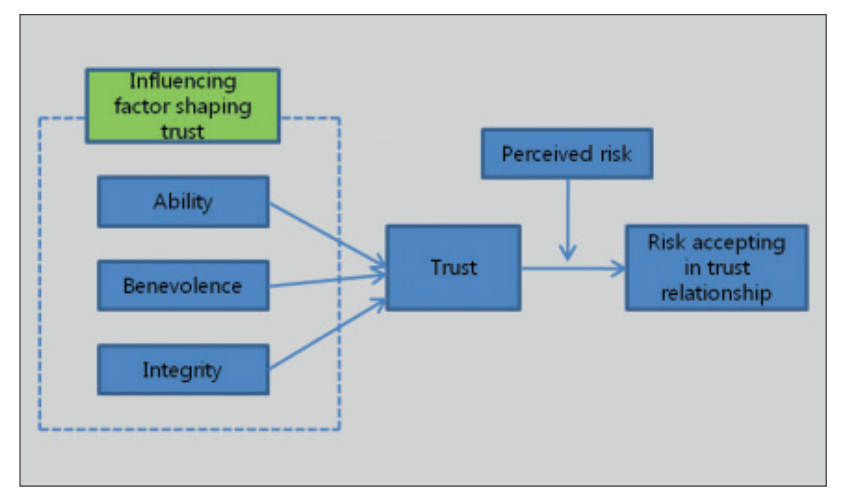

Fig. 3. Research model. 
595-602

iar place accepting risk despite perceiving travel anxiety is progressed. Tourists will get psychological stability escaping from anxiety symptom through these processes. It is certain the reason hotel web service needs trust. Trust will make the least loss of being brought about relationship (tangible or intangible loss by the travel anxiety) for achieving organizational and individual safe stay and emergency reaction. But this study didn't find causal relation among trust -shaping factors, perceived risk, and trust.

\section{Hypotheses setting}

We got the research model and hypotheses for empirical test based on prior theoretical studies $(7,14)$.

H1: Trust-shaping factors through website embedded VR will make positive influence on the trust.

To test above hypothesis, we test real survey data. There are assumptions through prior studies including;

1. Users will feel alleviating anxiety through VR website.

1.1 VR website will help alleviate anxiety.

1.2 VR website will help alleviate anxiety about public transportation around hotel.

1.3 VR website will help alleviate anxiety about convenience installations around hotel.

1.4 VR website will help alleviate anxiety about public guard and safety around hotel.

1.5 VR website will help alleviate anxiety about safe provisions around hotel.

1.6 VR website will help adequate activity under emergency.

2. Users will feel integrity through VR website.

2.1 Users feel hotel's kindness through VR website

2.2 Users feel convenience through VR website.

2.3 Users feel good hotel images through VR website.

3. Users will feel benevolence through VR website.

3.1 Users expect VR website is provided.

3.2 Users think VR website takes care of tourists with travel anxiety.

3.3 Users think VR website is adequate for them.

H2: Trust shaped through website embedded VR will make positive influence on the risk-taking.

We take assumptions to test $\mathrm{H} 2$ including;

4. For users to encounter VR website, they will rely on VR website and hotel.

4.1 If I tour 6 months below, I will use hotel providing VR website.

4.2 If I tour 6 months below, I will affiliate hotel or accommodations chain providing VR website.

4.3 I will lodge hotel or accommodations chain providing VR website.

4.4 I will actively recommend hotel or accommodations chain providing VR website.

5. For users to encounter VR website, they will determine to travel overcoming travel anxiety.

5.1 If some hotels serve VR website, I will lodge the hotel.

5.2 If some hotels serve VR website, I will prefer the hotel.
With above hypotheses, this study tests differences between VR with narration and VR without narration. We test hypothesis to help psychological stability about travel anxiety to serve VR embedded website with narrated video clip than serving VR embedded website without narrative.

H3: The embedded virtual reality website with narrated video clips provides more psychological relief than the embedded virtual reality website without narrated video clips.

\section{Questionnaire composition and analysis method}

This study is to test difference about effect of VR with narrative video clip or without narration on the hotel website implemented VR. Survey questionnaires are constructed based on research model and prior studies. Questionnaire contents are consisted of 30 items in 7 sections and are responded by 5 Likert scales excluding demographic items. Tab. 1 presents questionnaire construct. Each 100 samples by VR with narrative video clip or without narrative clip are extracted randomly by Internet bulletin or e-mail. Each 100 samples are used for analysis. The data gathering period is from $2011 / 5 / 10$ to $2011 / 5 / 31$. Statistical processing of data is used by PASW 18.0 (SPSS Inc.) including SPSS/AMOS package through data coding process by gathered data to test the hypotheses set.

\section{Empirical analysis}

\section{Demographic attributes}

Freqency analysis to know demographic attributes which are respondent's sex, age, travel frequency accompanying with accomodations outside, and anxiety symptoms was conducted. In the first case with narrated video, males are $63(63 \%)$ and females are $37(37 \%)$. Age of twenties are 91 (91\%). Travel frequency accompanying with accomodations outside is domestic 3.02 times and foreign 0.56 times. In the second case of VR without narration video, males are $66(66 \%)$ and females are $34(34 \%)$. Age of twenties are 94 (94\%). Travel frequency accompanying with accomodations outside is domestic 3.0 times and foreign 0.58 times.

\section{Pre-test for hypothesis testing}

Reliability analysis

Reliability degree is estimated using internal consistency index (Cronbach`s alpha) to analyze reliability. The alpha value is evaluated in reliable criterion at above 0.6 . Reliability index was presented to satisfactory level ranging from 0.786 to 0.916 .

\section{Confirmatory factor analysis}

Confirmatory factor analysis (CFA) is method using confirmatory purpose of common factor model in two factor analysis models. Chi-square is estimates more often used to evaluate null hypothesis which model is fit to data. But Chi-square estimate is very subjected to degree of freedom (3), so it hasn't been used alone. Namely, it has a problem that it is affected by sample size. It is recommended that goodness of fit indices quantified the degree of explanation by model about data variance and covariance is reported to evaluate independently goodness of fit apart from 
Tab. 1. Contents of questionnaire.

\begin{tabular}{|c|c|c|c|c|}
\hline Item & Variable & Item No. & Scale & Items sum \\
\hline Demographic elements & Sex, Age band, Travel frequency, anxiety symptoms $[10,15]$ etc. & - & Category & 6 \\
\hline \multirow{7}{*}{ Perception of travel anxiety } & Simple anxiety perception & Q7 1 & & \multirow{7}{*}{7} \\
\hline & Transportation tool anxiety perception & Q7_2 & & \\
\hline & Convenience installations anxiety perception & Q7_3 & & \\
\hline & Police order anxiety perception & Q7_4 & & \\
\hline & Safe installations anxiety perception & Q7_5 & & \\
\hline & Emergency behavioral anxiety perception & Q7 6 & & \\
\hline & Emergency accommodations anxiety perception & Q7_7 & & \\
\hline \multirow{6}{*}{ Website Ability } & Simple anxiety relief & Q8_1 & & \multirow{6}{*}{6} \\
\hline & Transportation tool anxiety relief & Q8_2 & & \\
\hline & Convenience installations anxiety relief & Q8 3 & & \\
\hline & Police order anxiety relief & Q8_4 & & \\
\hline & Safe installations anxiety relief & Q8 5 & Five & \\
\hline & Emergency behavioral anxiety relief & Q8_6 & Likert & \\
\hline \multirow{3}{*}{ Website benevolence } & Kind feeling & Q9_1 & & \multirow{3}{*}{3} \\
\hline & Convenient feeling & Q9_2 & & \\
\hline & Good image & Q9_3 & & \\
\hline \multirow{3}{*}{ Website Integrity } & Continuity forecasting & Q10_1 & & \multirow{3}{*}{3} \\
\hline & Considerate feeling & Q10_2 & & \\
\hline & Consistency feeling & Q10_3 & & \\
\hline \multirow{4}{*}{ Website trust } & Intention to use in the future & Q12_1 & & \multirow{4}{*}{4} \\
\hline & Intention to affiliation & Q12_2 & & \\
\hline & Intention to use hotel chain & Q12_3 & & \\
\hline & Intention to recommend & $\mathrm{Q} 12-4$ & & \\
\hline \multirow{3}{*}{ Website and risk accepting } & Intention to accommodate in the future & Q11_1 & & \multirow{2}{*}{2} \\
\hline & Preference of hotel & Q11_2 & & \\
\hline & Sum & & & 30 \\
\hline
\end{tabular}

degree of freedom (13). We selected CMIN/df (25), GFI and AGFI as absolute goodness of fit to evaluate model's overall fitness as well as CMIN. The incremental goodness of fit to evaluate proposed model's fitness is selected such as CFI and NFI. The parsimony goodness of fit to compare the difference between proposed model's complication and objectivity is selected such as PNFI and PCFI. It is interpreted as goodness of fit is good and recommended if CMIN/df is 5 below and GFI/NFI/CFI are .90 over. PNFI/PCFI are higher but recommendation level is .60 and AGFI is .80. Also, RMR (Root Mean square Residual), RMSEA (Root Mean Square Error of Approximation), and TLI are used for model's goodness of fit.

To test common factor model confirmatively about ability, benevolence, and integrity as three trust-shaping factors, Figure 16 is constructed. When the first confirmative factor analysis was implemented, unsatisfactory result of goodness of degree was presented. To improve goodness of fit, emergency behavioral anxiety relief (Q8_6) which is the lowest observable variance in ability factor in correlation analysis table is removed. As a result, test results of goodness of fit in VR with narration video clip are such as below.

Testing result to analyze theoretical model's goodness of fit presents CMIN $74.540(\mathrm{p}<0.05)$. Statistical significant difference was there between structure model and model presenting real data. CMIN/df got in considering sample size is 1.818 and this is fit to explain data well. RMR (.043), GFI (.883), AGFI (.812), IFI (.948), TLI (.929), CFI (.947), and NFI (.891) are presented and these values give higher model goodness of fit. PNFI and PCFI is over .60 and the proposed hypothesis model doesn't have sta- tistically significant difference compared to the empirical model representing real data. RMSEA index considering model's parsimony is .091. RMSEA (<.10) can be accepted. GFI (.883) and NFI (.891) are lower than .90 but these values are interpreted near to model's goodness of fit.

In VR without narration video clip, emergency behavioral anxiety relief variable (Q8_6) is removed and confirmatory factor analysis is implemented. CMIN $62.280(\mathrm{p}<0.05)$ as testing result to analyze theoretical model's goodness of fit are presented. Statistically significant difference was there between structure model and model presenting real data. CMIN/df got in considering sample size is 1.519 and this is fit to explain data well. RMR (.046), GFI (.899), AGFI (.832), IFI (.961), TLI (.946), CFI (.960), and NFI $(.893)$ are presented and these values give higher model goodness of fit. PNFI and PCFI is over .60 and the proposed hypothesis model doesn't have statistically significant difference compared to the empirical model representing real data. RMSEA (.072) can be accepted. GFI (.899) and NFI (.893) are lower than .90 but these values are interpreted near to model goodness of fit.

\section{Hypothesis testing}

Frequency analysis

This study converted frequency into percentage considering basic attributes to know tendency through frequency analysis. After classifying one of survey respondents' 'never do' or 'sometimes do not' or 'neutral' or 'often do' or 'always do' response, we tried to test statistical significance of the number of frequency through each item's $\chi^{2}$ testing. 


\section{Linear regression analysis}

To analyze causal relation among trust shaping factors of ability, benevolence, integrity, and trust, multi-regression each case of VR with narration video or VR without narration video is implemented. Also, simple regression analysis about trust and risk -accepting is implemented.

When judging multi-regression model's F value 37.349 and adjusted $\mathrm{R}^{2}$ value .542 in reciprocal relation between trust-shaping factor and trust, ability, benevolence, and integrity explain $52.4 \%$ about trust-shaping. There has no problem in multi-collinearity among independent variables in seeing Tolerance $(>.1)$ and VIF $(<10)(19)$.

Ability factor $(\mathrm{t}=4.037, \mathrm{p}=.000)$ and benevolence factor $(t=3.087, p=.003)$ affecting trust in t-value's degree of significance are significant under significant level .01. Non-standardized regression coefficient value of ability factor is .396 and influencing power is .343 . Non-standardized regression coefficient value of benevolence factor is .325 and influencing power is .331 and presents influencing power affecting trust-shaping. Integrity factor $(\mathrm{t}=1.635, \mathrm{p}=.105)$ is not significant statistically under significant level .05 but it affects positively degree of trust and non-standardized coefficient value is .209 and influencing power is .187.

When judging simple regression model's F value 112.158 and adjusted $\mathrm{R}^{2}$ value .529 in reciprocal relation between trust factor and risk-accepting, trust explains $52.9 \%$ about risk-accepting. There has no problem in multi-collinearity among independent variables in seeing Tolerance $(>.1)$ and VIF $(<10)$.

Trust ( $\mathrm{t}=10.590, \mathrm{p}=.000)$ affecting risk-accepting in t-value's degree of significance are significant under significant level .01. Non-standardized regression coefficient value of trust factor is .740 and influencing power is .731 so trust can explain risk-accepting adequately.

These below present regression analysis results in VR without narration video. The results of multi-regression analysis to figure out trust-shaping factor's making influence on trust are presented below. As we see the model presents F value 35.974, determinant coefficient (adjusted $\mathrm{R}^{2}$ value) .515 , ability, benevolence, and integrity explain trust-shaping as $51.5 \%$. There has no problem in multi-collinearity among independent variables in seeing Tolerance $(>.1)$ and $\operatorname{VIF}(<10)$. Also, ability factor $(\mathrm{t}=3.046, \mathrm{p}=.003)$, benevolence factor $(t=3.039, \mathrm{p}=.003)$, and integrity factor $(\mathrm{t}=3.100$, $\mathrm{p}=.003$ ) are significant under $\mathrm{p}<.01$. Ability factor's unstandardized regression coefficient (.273), influencing power (.243), benevolence factor's unstandardized regression coefficient (.289), influencing power (.304), and integrity factor unstandardized regression coefficient (.341), influencing power (.324) present influencing power to trust-shaping.

The results of simple regression to figure out influence on riskaccepting of trust factor are presented below. As we see what the model presents $\mathrm{F}$ value 134.350 , adjusted $\mathrm{R}^{2}$ value (.574), trust explain risk-accepting as $57.4 \%$. There has no problem in multicollinearity among independent variables in seeing Tolerance $(>.1)$ and VIF $(<10)$. Trust factor's unstandardized coefficient (.820) and influencing power (.760) presents adequately influencing power to risk accepting. Trust ( $\mathrm{t}=11.591, \mathrm{p}=.000)$ affecting risk-accepting in t-value's degree of significance are statistically significant under significant level $(\mathrm{p}<.01)$. Non-standardized regression coefficient value of trust factor is .820 and influencing power is .760 so trust explains adequately risk-accepting.

\section{Independent Samples t-Test}

This t-Test is to analyze differences of two groups. The principle of t-Test is to test whether two group's average is significantly different using two group's variance and sum of two group's variance. The assumption of variance homogeneity is tested prior to t-Test process. This study tests the difference (hypothesis) of website's ability, benevolence, integrity, trust, and risk-accepting whether VR with narration video or without it.

Trust-shaping factors' average is 3(normal) over whether narration video is or not. So it's thought most respondents respond positively about website's ability, benevolence, integrity, trust, and risk-accepting of VR. Also, it proceeded to test variance homogeneity using Levene's test to make independent samples t-Test useful (Tab. 2).

The results of independent samples t-Test present ability factor (F-value .024, significant probability .876), benevolence factor (F-value .296, significant probability .587), integrity factor (F-value .222, significant probability .638), trust factor (F-value .117 , significant probability .733 ), and risk-accepting factorm (F-value .511, significant probability .475). Those explain they have variance homogeneity under significant probability .05. Test statistic in "variance homogeneity assumption" is used. As a result, ability factor ( $\mathrm{t}$ value 3.817 , $\mathrm{p}$-value .000 under $\mathrm{p}<.01$ ),

Tab. 2. The difference testing with narration video or without it.

\begin{tabular}{|c|c|c|c|c|c|}
\hline Variable & With narration video or without it & Average & S. D. & t-value & P-value \\
\hline \multirow{2}{*}{ Ability } & With & 3.5580 & .68831 & \multirow{2}{*}{$3.817 * *$} & \multirow{2}{*}{.000} \\
\hline & Without & 3.1860 & .69005 & & \\
\hline \multirow{2}{*}{ Benevolence } & With & 3.8000 & .80959 & \multirow{2}{*}{$2.089 *$} & \multirow{2}{*}{.038} \\
\hline & Without & 3.5600 & .81496 & & \\
\hline \multirow{2}{*}{ Integrity } & With & 3.9200 & .71086 & \multirow{2}{*}{$2.152 *$} & \multirow{2}{*}{.033} \\
\hline & Without & 3.7000 & .73474 & & \\
\hline Trust & With & 3.5025 & .79574 & 1.621 & .107 \\
\hline \multirow{2}{*}{ Risk accepting } & With & 3.5500 & .80560 & \multirow{2}{*}{1.853} & \multirow{2}{*}{.065} \\
\hline & Without & 3.3225 & .83501 & & \\
\hline
\end{tabular}

$* \mathrm{p}<.05, * * \mathrm{p}<.01$ 
benevolence factor ( $\mathrm{t}$ value 2.089, $\mathrm{p}$-value .038 under $\mathrm{p}<.05$ ), and integrity factor ( $\mathrm{t}$ value $2.152, \mathrm{p}$-value .033 under $\mathrm{p}<.05$ ) has significant difference by website's VR with narration video or not. Whereas, trust factor ( $\mathrm{t}$ value 1.621, p-value .107 under $\mathrm{p}<.05$ ) doesn't have significant difference by website's VR with narration video or not. Risk-accepting factor ( $\mathrm{t}$ value 1.853 , $\mathrm{p}$ value .065 under $\mathrm{p}<.05$ ) doesn't have significant difference by website's VR with narration video or not.

\section{The abstract and analysis about hypothesis testing}

To see overall research, survey in website embedded VR with narration video presented more significantly positive reaction. Website providing VR without narration video had lower reaction especially to ability factor. But website with VR whether narration video is or not was effective.

At first, ability, benevolence, and integrity as trust shaping factor have positive influence on trust of hotel website embedded VR whether narration video is or not. Those factors have different influences on trust and different whether VR with narration video or not. In case of VR with narration video, trust shaping about integrity was slightly affected.

Second, it was tested trust shaped by website embedded VR affects positively risk accepting. Trust shaped by ability, benevolence, and integrity have causal relation to shape risk accepting. Namely, users feel trust through ability, benevolence, and integrity by hotel website embedded VR whether narration video is or not and they have an intention for using hotel by shaped trust.

Finally, there are difference among each factor as ability, benevolence, and integrity shaping trust whether narration video is or not. This study presents difference is statistically significant by t-test that the case with narration video has more significant than the other case without narration video. But this doesn't explain the difference between trust and risk accepting. Though there was no difference whether narration video is or not in users' behaviors and self-efficacy (1), we can understand that difference was found in the aspect of website ability, benevolence, and integrity about VR users feel.

\section{Conclusions}

\section{Research abstract and suggestions}

Even this study did not testing for real tourists but it was executed assuming conditions setting like experiencing real travel circumstances. It studied effects on human activity by using virtual reality applied to hotel web site. As a result, we got both of reliable and meaningful outcomes statistically. In testing two hypotheses of $\mathrm{H} 1$ and $\mathrm{H} 2$, whether VR with narration video or without website with VR help users feel ability, benevolence, and integrity and even visit tour site and accommodate to hotel. But in testing most important hypothesis $\mathrm{H} 3$ as see totally, it presents no statistical difference between trust and risk accepting. In detail, only VR without narration video has effect for alleviating travel anxiety. We expected more effect in VR with narration video but this couldn't explain the difference of real travel and accomodations activities.

\section{Study limitation and further study}

In designing research model first, it assumed there is no difference by age about degree of risk-perceiving (23). But, twenties respondents most actively using Internet had much more portions because of random sampling by online. So, the result of survey had tendency of decreasing risk-perceiving in travel as their ages are less (9). Thus, travel anxiety perceiving factor included the first research model was removed to help hypothesis testing. If more various age bands participated in survey, survey results could be different or various. Most of respondents perceived VR were relieved from travel anxiety and VR with narration video was more effective. This point provides suggestion to lodging suppliers around world because it is reported that 10 30 percent adults around world have anxiety (24). The more anxious people are, the more helpful this kind of website is. If research subjects were to limited to people having anxiety trouble to overcome these study limitations, it would be more sophisticate testing about travel anxiety hypotheses. If VR with narration video apply to not only hotel website but also website guiding various places and to more platforms or devices including tablet pad and smart-phone, it will be helpful to not only travelers with anxiety but general tourists.

\section{References}

1. Bandura A. Self-efficacy: The Exercise of Control. New York: WHFreeman, 1997.

2. Barlow D. Anxiety and its disorders: The nature and treatment of anxiety and panic. New York: NThe Guilford Press, 2004.

3. Bentler PM, Bonett DG. Significance tests and goodness of fit in the analysis of covariance structures. Psychol Bull 1980; 88: 37-51.

4. Wiederhold BK. The Potential for Virtual Reality to Improve Health Care. The Virtual Reality Medical Center, 2006.

5. Carr N. An Exploratory Study of Gendered Differences in Young Tourists' Perception of Danger within London. Tourism Management 2001; 22: $565-570$.

6. Carter S. Tourists and Traveler's Social Construction of Africa and Asia as Risky Locations. Tourism Management 1988; 19: 349-358.

7. Dowling G, Staelin R. A Model of Perceived Risk and Intended RiskHandling Activity. J Consumer Res 1994; 21 (1): 119-135.

8. Foa EB, Kozak MJ. Emotional processing of fear: Exposure to corrective information. Psychol Bull 1986; 99: 20-35.

9. Gibson H, Yiannakis A. Tourist roles, perceived risk and international tourism. Ann Tourism Res 2002; 30 (3): 606-624.

10. Gudykunst W, Hammer M. Strangers and Hosts: An Uncertainty Reduction Base Theory of Intercultural Adaptation. 106-139. In: Kim Y, Gudykunst W (Eds). Cross-Cultural Adaptation: Current Approaches. Newbury Park, CA: Sage, 1988.

11. Hodges L, Rothbaum BO, Kooper R, Opdyke D, Meyer T, de Graaf JJ, Williford JS. Presence as the defining factor in a VR application.. Technical report GIT-GVU-94-5, Georgia Institute of Technology, 1994.

12. Lee $\mathbf{O}, \mathbf{O h} \mathbf{J}$. The Impact of Virtual Reality Functions of a Hotel Website on Travel Anxiety. Cyberpsychol Behavior 2007; 10 (4): 584-586. 
$595-602$

13. Marsh HW, Balla JR, McDonald RP. Goodness-of-fit indexes in confirmatory factor analysis: The effect of sample size. Psychol Bull 1988; 103: 391-411.

14. Mayer RC, Davis JH, Schooman FD. An Integrative Model of Organizational Trust. Acad Management Rev 1995; 20 (3): 709-734.

15. McIntyre N, Roggenbuck J. Nature/Person Transactions during an Outdoor Adventure Experience: A Multi-Phasic Analysis. J Leisure Res 1998; 30 (4): 401-422.

16. Spiegler MD, Guevremont DC. Contemporary Behavior Therapy (4th ed). Florence, KY: Wadsworth Publishing Company, 2002.

17. Mitchell VF, Davies L, Moutinho, Vassos V. Using Neural Networks to Understand Service Risk in the Holiday Product. J Business Res 1999; 46 (2): 167-180.

18. North MM, North SM, Coble JR. Effectiveness of Virtual Environment Desensitization in the Treatment of Agoraphobia. Presence: Teleoperators Virtual Environ 1996; 5: 346-352.

19. O'Brien RM. A Caution Regarding Rules of Thumb for Variance Inflation Factors. Quality Quantity 2007; 41 (5): 673-690.
20. Pull C. Current Status of Virtual Reality Exposure Therapy in Anxiety Disorders: Editorial Review. Curr Opin Psychiat 2005; 18 (1): 7-14.

21. Reisinger Y, Mavondo F. Travel Anxiety and Intentions to Travel Internationally: Implications of Travel Risk Perception. J Travel Res 2005; 43 (3): 212-225.

22. Slater M, Pertaub D, Steed A. Public speaking in virtual reality: Facing an audience of avatars. IEEE Computer Graph Appl 1999; 19: 6-9.

23. Sonmez S, Graefe A. Influence of Terrorism Risk on Foreign Tourism Decisions. Ann Tourism Res 1998; 25 (1): 112-144.

24. Taylor S, Koch W, McNally R. How does anxiety sensitivity vary across the anxiety disorders? J Anxiety Dis 1992; 6 (3): 249-259.

25. Wheaton B, Muthen B, Alwin DF, Summers GF. Assessing reliability and stability in panel models. 84-136. In: Heise DR (Ed). Sociological methodology 1997. San Francisco: Jossey-Bass, 1977.

26. Travel Anxiety Symptoms by Karen M Holt, eHow Contributor. Read more: Travel Anxiety Symptoms. http://www.ehow.com/about_5108477_ travel-anxiety-symptoms.html\#ixzz160YAF1QC

Received November 3, 2011. Accepted July 20, 2013. 